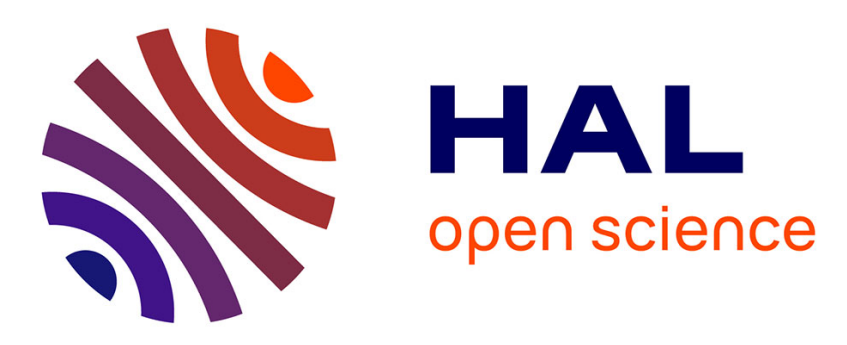

\title{
Viscoelastic properties of multi-walled carbon nanotube/epoxy composites using two different curing cycles
}

Arash Montazeri, Alireza Khavandi, Jafar Javadpour, Abbas Tcharkhtchi

\section{- To cite this version:}

Arash Montazeri, Alireza Khavandi, Jafar Javadpour, Abbas Tcharkhtchi. Viscoelastic properties of multi-walled carbon nanotube/epoxy composites using two different curing cycles. Materials \& Design, 2010, 31 (7), pp.3383-3388. 10.1016/j.matdes.2010.01.051 . hal-02456698

\section{HAL Id: hal-02456698 \\ https://hal.science/hal-02456698}

Submitted on 10 Feb 2020

HAL is a multi-disciplinary open access archive for the deposit and dissemination of scientific research documents, whether they are published or not. The documents may come from teaching and research institutions in France or abroad, or from public or private research centers.
L'archive ouverte pluridisciplinaire HAL, est destinée au dépôt et à la diffusion de documents scientifiques de niveau recherche, publiés ou non, émanant des établissements d'enseignement et de recherche français ou étrangers, des laboratoires publics ou privés. 


\title{
Viscoelastic properties of multi-walled carbon nanotube/epoxy composites using two different curing cycles
}

\author{
Arash Montazeri ${ }^{\mathrm{a}, *}$, Alireza Khavandi ${ }^{\mathrm{a}}$, Jafar Javadpour ${ }^{\mathrm{a}}$, Abbas Tcharkhtchi ${ }^{\mathrm{b}}$ \\ ${ }^{a}$ Department of Materials Science and Engineering, Iran University of Science and Technology (IUST), Narmak, 16844 Tehran, Iran \\ ${ }^{\mathrm{b}}$ Laboratoire d'ingénierie des matériaux, ENSAM-Paris, 151 bd de L'Hôpital, Paris, France
}

Keywords:

A. Carbon nanotubes

C. Curing cycle

E. Mechanical properties

E. Viscoelastic properties

E. Modeling

\begin{abstract}
A B S T R A C T
Along with carbon nanotubes (CNT) morphology, impurity, and functionalization, polymer curing cycle is another important factor in determining the mechanical properties of the CNT/polymer composite samples. This work investigates the effect of two different curing cycles on mechanical and thermo-mechanical properties of the nanotube in the composite in order to optimize the curing condition in term of time and temperature. Nanocomposite samples were prepared by mixing multi-wall carbon nanotubes with epoxy resin using sonication method. The mechanical and viscoelastic properties of the resulting composite samples were evaluated by performing tensile and dynamic mechanical thermal analyses (DMTA) test. The results indicate that the mechanical and viscoelastic properties of pure epoxy and composite samples have been affected by the condition curing process. Concerning viscoelastic modeling, the COLE-COLE diagram has been plotted by the result of DMTA tests. These results show a good agreement between the Perez model and the viscoelastic behavior of the composite.
\end{abstract}

\section{Introduction}

Since the discovery of carbon nanotubes (CNTs) by arc discharge method in 1991 [1], many research activities have been focused on CNT-related fields. Carbon nanotubes have excellent mechanical and electrical properties and are also good reinforcing material for composites. Nanotubes exist in the form of multi-walled nanotubes (MWNT) discovered by Iijima and Icihashi [2] and singlewalled nanotubes (SWNT) discovered by Bethune et al. [3]. MWNT have unique atomic structure, very high aspect ratio, and extraordinary mechanical properties, making them ideal reinforcing materials in nanocomposites [4]. Among various polymers, epoxy resin is the most common class of thermosetting resin used in various applications because of their high tensile strength and modulus, low shrinkage in cure, good chemical and corrosion resistance, high adhesion and dimensional stability. The main drawback of epoxy resins for structural applications may be its inherent brittleness. Thus, several research works have recently been devoted to reinforcement of epoxy matrixes with CNTs. Nanotube-reinforced epoxy system hold the promise of delivering superior composite materials with high strength, light weight and good electrical conductivity (1000 times higher than copper) for aircraft, space shuttle and electronic products $[5,6]$. In practice, however, many experiments indicate that carbon nanotube/epoxy composites are weaker or only slightly stronger than neat epoxy [7]. This has been

\footnotetext{
* Corresponding author. Tel.: +98 9111933562; fax: +98 2177491206

E-mail address: A_Montazeri@iust.ac.ir (A. Montazeri).
}

found to be related to several factors, namely poor MWNT dispersion, inadequate alignment and weak interfacial bonding [7-10]. Therefore, in order to achieve optimal enhancement in the properties of CNT/polymer composites, two key issues should be considered: homogeneous dispersion of CNTs in the polymer resin and strong interfacial bonding between the CNTs and the polymer matrix. Concerning the homogeneous dispersion of nanotube in matrix, the research results indicate that combining solvent dilution with tip sonication method is an effective method for improving MWNT dispersion and enhancing the storage modulus and glass transition temperature $\left(T_{g}\right)$ of MWNT/epoxy nanocomposite [7,11-13].

In order to have a strong interfacial bonding between the nanotubes and the polymer matrix, it is necessary to perform the surface treatment of nanoparticles before mixing them with polymer matrix. Mitchell et al. [14] examined the linear viscoelastic properties of composite prepared with pristine SWCNT and organically modified SWCNT in polystyrene matrix. It was found that the composite filled with functionalized CNTs had better dispersion and showed higher modulus. Abdalla et al. [15] showed that by using carboxylic and fluorinated nanotubes the storage modulus in the glassy state and the rubbery plateau modulus were higher compared to the neat epoxy. The microscopic analysis, DMTA is also another effective way to investigate the dispersion state and viscoelastic properties. In the field of polymers the study of viscoelastic behavior is very important because other properties are related to this behavior. In this study, we are interested particularly in viscoelastic behavior of nanocomposites. The question is: 
"what is the effect of nanoparticles on this property?" Factually in nanoscales, the particles can have important effect on the physical properties of matrix such as free volume, density, and local molecular motion. In this field, few studies have been reported, so the study of these effects on viscoelastic behavior of matrix is not without interest. One way to study the viscoelastic behavior of polymer is modeling. By modeling, we can compare one polymer to another; study the effect of additives and fillers on the properties of a polymer; and also follow the evolution of polymer in its application period. Modeling based on COLE-COLE diagram is one of the methods to study the viscoelastic behavior of polymers. This modeling method can give us the predictive information about elastic and viscous properties independently.

There are different models in literature among which the Perez model [16-18] is reported as an appropriate model for amorphous polymer (polyepoxy for example).

The effect of frequency on the dynamic mechanical response of polymers is well documented. An increase in test frequency will shift the peak of the tangent (delta) curve to a higher temperature [19-21,22]. This phenomenon is based on the fundamental relationship between the temperature and the frequency of molecular conformation change in polymers [22]. The effect of the temperature on the frequency of conformational change, such as the glass transition relaxation, is explained by a form of the Arrhenius equation. The activation energy of the glass transition relaxation can be estimated using DMTA testing of a polymer at different test frequencies [23].

Due to the fact that, there has been no systematic investigation on the effect of curing cycles on the viscoelastic properties and modeling of this behavior in carbon nanotube composites. This paper describes the manufacturing process of MWNT/epoxy composites, applying two different curing cycles, and investigating their effect on the mechanical and viscoelastic properties using Perez models. The nanotubes dispersion and viscoelastic properties were investigated through scanning electronic microscopy (SEM) and dynamic mechanical thermal analysis (DMTA).

\section{Experimental study}

\subsection{Materials}

The multi-walled carbon nanotubes (MWNT), used in this study, were supplied by Research Institute of Petroleum Industry (Iran). They were synthesized by chemical vapor deposition with the diameter of 10-20 nm. The epoxy resin Ly564 (Araldite) which has low viscosity and the hardener Hy560 (Aradur) used were supplied by Huntsman Company. They are respectively based on diglycidyl ether bisphenol-A (DGEBA) and polyamine. The MWNT were purified by a $3: 1(\mathrm{vol} / \mathrm{vol})$ mixture of concentrated sulfuric acid (98\%) and nitric acid (65\%) for removing impurities such as amorphous carbon, graphite particles, and metal catalyst.

\subsection{Curing cycles}

Two curing cycles were applied: in cycle A, the epoxy was hardened at $80^{\circ} \mathrm{C}$ for $4 \mathrm{~h}$. In cycle B, the system was cured for $24 \mathrm{~h}$ at room temperature and post cured at $80^{\circ} \mathrm{C}$ for $4 \mathrm{~h}$. These curing cycles were selected using thermo-gram of DSC (Fig. 1). As indicated, the curing started at room temperature (RT) and finished at $130^{\circ} \mathrm{C}$.

\subsection{Composites preparation}

MWNT (0.5 wt.\%) was mixed with epoxy at $80^{\circ} \mathrm{C}$. The mixture was then sonicated (Bandelin HD3200, $20 \mathrm{kHz}$ ) for $2 \mathrm{~h}$ at $60 \%$ amplitude on pulse mode, 50-s on/25-s off. After sonication, the

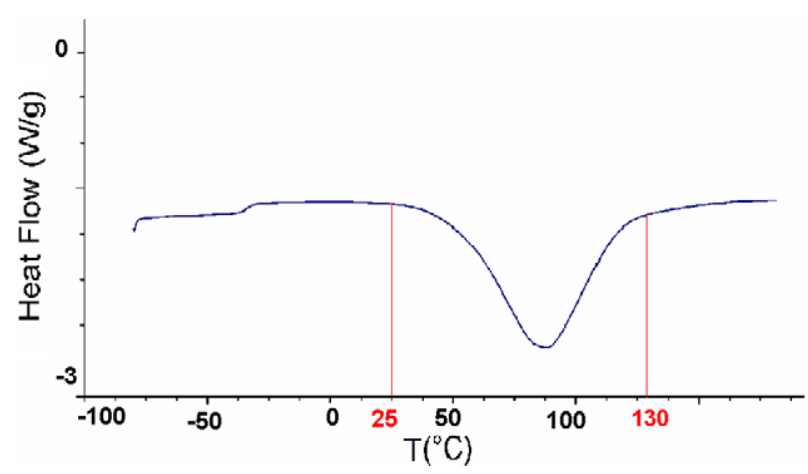

Fig. 1. DSC scans of neat epoxy.

hardener was added to the mixture and stirred for $10 \mathrm{~min}$ at $150 \mathrm{rpm}$. This process was followed by placing the mixture under vacuum to remove air bubbles.

\subsection{Analytical methods}

All the MWNT/Ly564 nanocomposites and the neat resin samples were mechanically polished to minimize the influence of surface flaw, mainly the porosity. Tensile tests were carried out at $25^{\circ} \mathrm{C}$ using Hounsfield machine (model H100KS, Hounsfield static tension load cell of capacity $10 \mathrm{KN}$ ) and an extensometer (Instron dynamic extensometer with $12.5 \mathrm{~mm}$ gauge) was used to record tensile strength, elongation and modulus values. The samples were loaded to failure at a cross-head speed of $1.5 \mathrm{~mm} / \mathrm{min}$. The choice of this quite low loading rate was due to the brittle nature of composites. Four dog-bone shaped specimens (ASTM D638-IV) were used for each measurement [24]. The investigation of the viscoelastic behavior was performed by dynamic mechanical thermal analysis, DMTA, using a Netzsch DMA 242 machine. For these measurements, rectangular specimens of $60 \mathrm{~mm}$ length, $9 \mathrm{~mm}$ width, and $2.5 \mathrm{~mm}$ thickness were prepared. The first sets of tests were performed in the tensile mode at a frequency of $1 \mathrm{~Hz}$ with a heating rate of $2{ }^{\circ} \mathrm{C} / \mathrm{min}$. The second set of tests, specimens were tested at frequencies of $0.1,0.5,1,5,10,20$, and $25 \mathrm{~Hz}$ with a heating rate of $0.2^{\circ} \mathrm{C} / \mathrm{min}$. Kinetic of cross linking was studied by DSC on the TA instrument (Q1000). The cryogenic fracture surface analysis was performed by scanning electron microscope (SEM, model LX 30 at $20 \mathrm{kV}$ ). The samples were coated with a thin layer of gold prior to examination by SEM.

\section{Results and discussion}

\subsection{Evaluation of tensile properties}

The mechanical properties of the pure epoxy and two composite materials following cycles A and B are given in Table 1. Epoxy matrix reinforced with $0.5 \mathrm{wt} . \%$ in weight of MWNT showed an increase in the Young's modulus and tensile strength by both curing processes. According to Table 1, more improvement are observed with the cycle A. The improvement in the Young's

Table 1

Mechanical properties of pure epoxy and two composite materials following cycles A and $\mathrm{B}$.

\begin{tabular}{llll}
\hline Material & $E(\mathrm{MPa})$ & $\sigma_{u}(\mathrm{MPa})$ & $\varepsilon_{f}(\%)$ \\
\hline Epoxy (A) & 3248 & 70 & 3.4 \\
MWNT/epoxy (A) & 3368 & 73 & 3.7 \\
Epoxy (B) & 3640 & 75.3 & 5.9 \\
MWNT/epoxy (B) & 3726 & 76.1 & 4.5 \\
\hline
\end{tabular}


modulus of epoxy samples with cycles A and B with the addition of 0.5 wt.\% MWCNT were $3.7 \%$ and $2.3 \%$ respectively. Also, the improvement in tensile strength of epoxy samples with the addition of 0.5 wt.\% MWCNT were $4.2 \%$ and $1 \%$ respectively. It is obvious that MWCNT acts as reinforcing agent in the epoxy matrix for two cycles. However, the improvement becomes less noticeable with the increase in curing time under isothermal condition. Similar results have been reported in the literature [25,26]. Comparing the two curing cycles, the increment of the Young's modulus of the epoxy and composite seems to be affected by the curing process. Also, comparing the two curing cycles, the modulus increment of the composite is similar to the epoxy resin.

Fig. 2a and b represents the SEM images of the fracture surface of composite samples. As shown in these figures, the fracture surface of the cycle B composite is very rough, indicating that the failure was accompanied with plastic deformation [25,26]. However, the smooth fracture surface of the cycle A composite suggests a more brittle type of failure.

As seen in Fig. 3, the materials cured by cycle B are stiffer and show higher toughness compared to materials treated by cycle $A$. Stiffness of materials could be increased by the curing cycle.

\subsection{Viscoelastic behavior}

The storage modulus and the damping properties of the nanocomposites were investigated by DMTA. Fig. 4a shows the results of dynamic measurement of storage modulus as a function of temperature. The addition of nanotubes to the epoxy has a slightly effect on the rubbery regions. However, a strong increase was observed in the storage modulus in glassy regions and in the vicinity of the glass transition temperature. An improved interaction between the nanotubes and the epoxy matrix leads to stronger
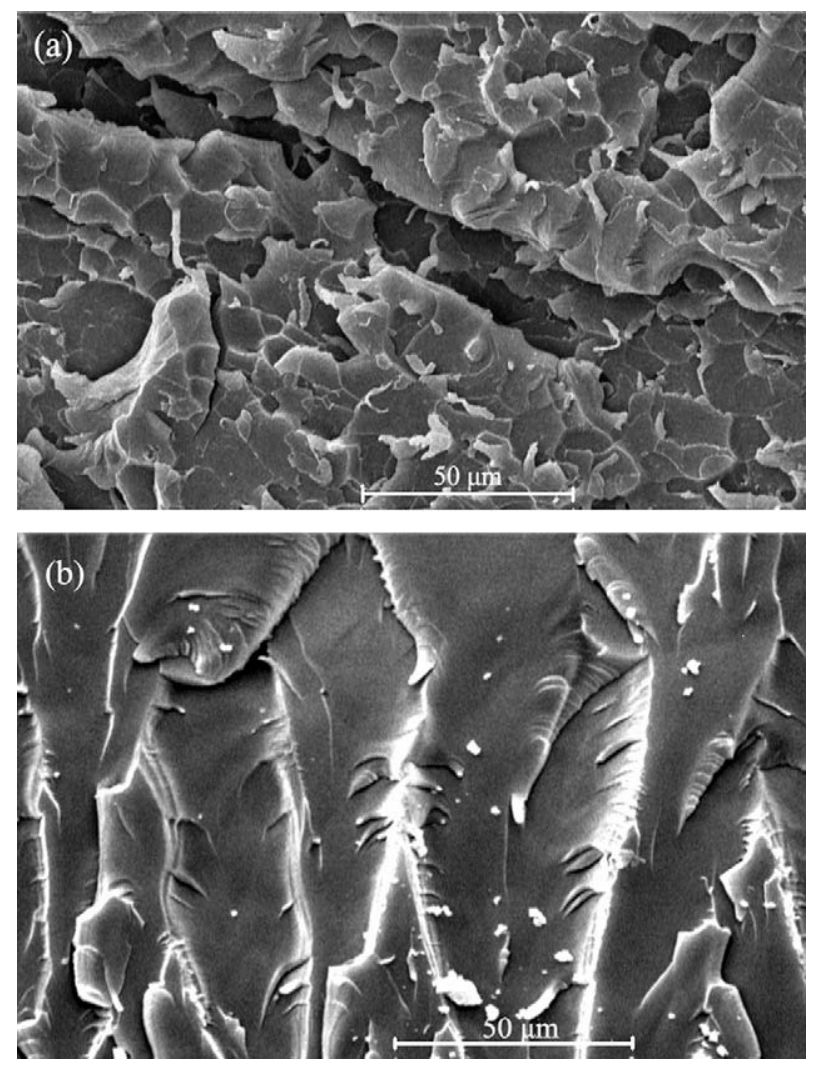

Fig. 2. SEM image of the fracture surface MWNT-epoxy composite: (a) cycle B and (b) cycle A.

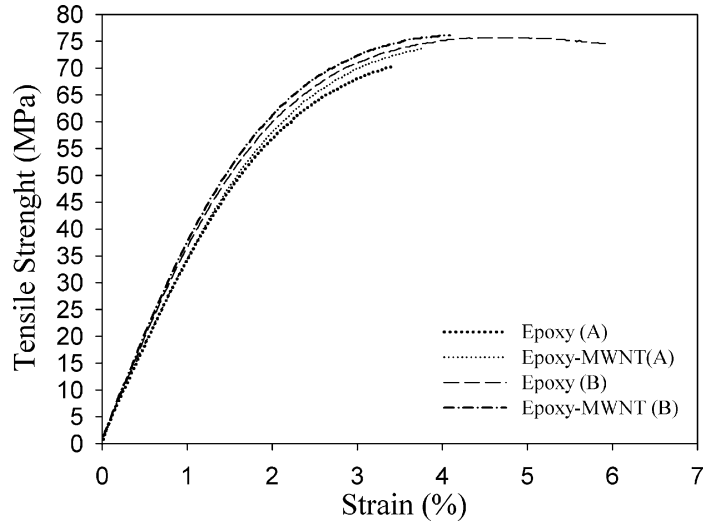

Fig. 3. Stress-strain curves of epoxy and composite in two different cycles.

shift of the elastic properties of the epoxy system below the rubbery region. The behavior could be explained in terms of an interaction between the nanotubes and the epoxy due to enormous surface area. This interfacial interaction reduces the mobility of the epoxy matrix around the nanotubes and leads to an observed increase in thermal stability [10]. A strong increase of storage modulus, especially above $T_{g}$ could not be expected for nanotube contents used in this study. In fact in this state, the molecular motion and the amplitude of this motion are very high and the macromolecule is not practically in contact with particles. So, there is no shear force between them.

For the whole range of temperatures, the nanocomposites of cycles $A$ and $B$ exhibit higher storage modulus than that of epoxy. But
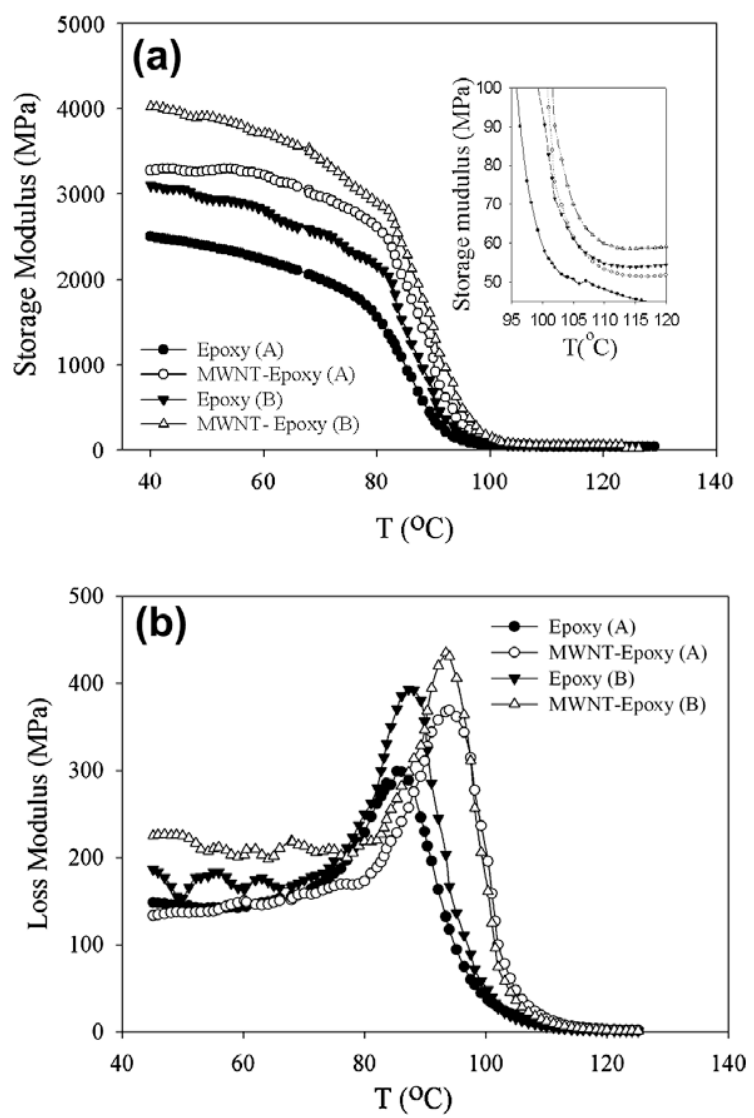

Fig. 4. Storage modulus (a) and loss modulus (b) of neat epoxy and MWNT/epoxy for cycles $A$ and $B$. 
the increment of storage modulus composite cycle $\mathrm{A}$ above $45^{\circ} \mathrm{C}$ is more than that of cycle $B$.

Beside the influence on the elastic properties, the addition of nanotubes to the epoxy has increased the loss modulus in both cycles A and B (Fig. 4b). The dispersed nanotubes dissipate energy due to resistance against viscoelastic deformation of the surrounding epoxy matrix. For the four materials examined, the loss factor $(\tan (\delta))$ shows a sharp peak above $95^{\circ} \mathrm{C}$ which indicates a glassto-rubbery transition in the polymer, i.e. the glass transition temperature $\left(T_{g}\right)$ (see Fig. 5). The addition of nanotubes to the epoxy results in a shift of glass transition temperature. $T_{g}$ was shifted from $93{ }^{\circ} \mathrm{C}$ for the neat resin, to $101^{\circ} \mathrm{C}$ for the cycle A composite, and from $94.3{ }^{\circ} \mathrm{C}$ to $100.3{ }^{\circ} \mathrm{C}$ for the cycle B composite. The shifting in $T_{g}$ towards higher values for the nanocomposites indicates that the nanotubes tend to restrict the mobility of the polymer chains in the matrix.

The results of tensile and DMTA tests indicated that prolonging the curing time reduce the enhancement of mechanical and viscoelastic properties. This might be due to the fact that the introduction of carbon nanotubes has no effect on the maximum cure degree of epoxy $[27,28]$, and the nanotube effect decreases by increasing the curing time. In our system as the curing time is not optimized, $T_{\mathrm{g}}$ is improved because of curing time and nanotube percentage. But when we use an optimized condition, the improvement of $T_{g}$ is only related to the presence of nanotube. So, it is obvious that the effect of nanotubes is more pronounced for a resin that was cured at a lower time. The cured samples were investigated by DSC to ensure completed curing reaction and to exclude a possible influence of the degree of cross linking on $T_{g}$. Fig. 6 Shows DSC-

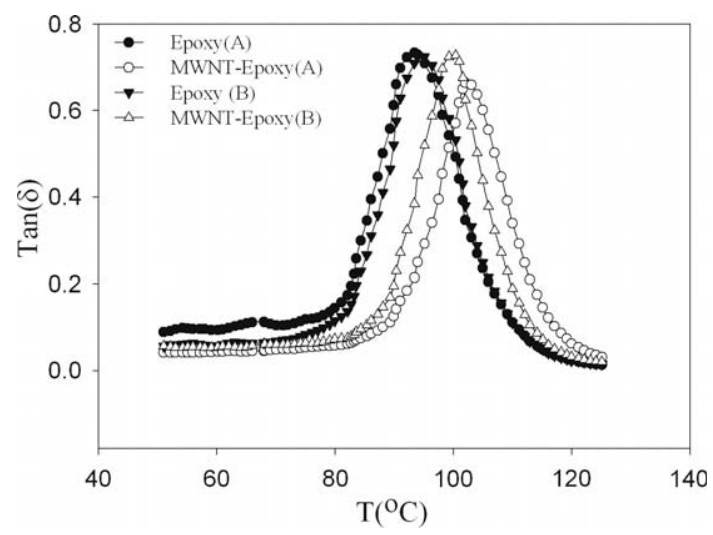

Fig. 5. Loss $\tan (\delta)$ of MWNT/epoxy for cycles A and B.

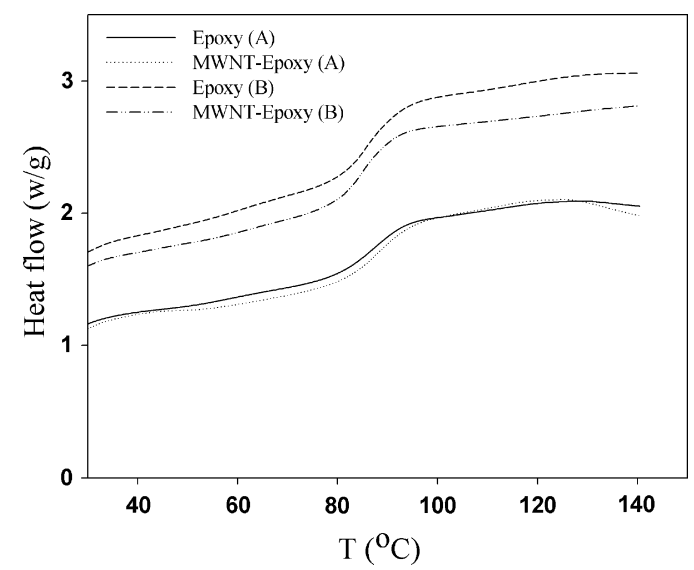

Fig. 6. DSC-curves of neat epoxy and MWNT/epoxy composites for cycles A and B.
Table 2

$T_{g}$ vs. frequency for neat epoxy and composite materials.

\begin{tabular}{lccrc}
\hline $\begin{array}{l}\text { Frequency } \\
(\mathrm{Hz})\end{array}$ & $\begin{array}{l}\text { Epoxy } \\
(\mathrm{A})\end{array}$ & $\begin{array}{l}\text { MWNT/epoxy } \\
(\mathrm{A})\end{array}$ & $\begin{array}{l}\text { Epoxy } \\
(\mathrm{B})\end{array}$ & \multicolumn{1}{l}{$\begin{array}{l}\text { MWNT/epoxy } \\
(\mathrm{B})\end{array}$} \\
\hline 0.1 & 90 & 90.7 & 93.7 & 93 \\
0.5 & 94 & 93.7 & 96.7 & 96 \\
1 & 95 & 94.8 & 98.7 & 97 \\
5 & 99 & 98.8 & 102.7 & 101 \\
10 & 101 & 100.8 & 104.7 & 105 \\
20 & 103 & 101.8 & 105.7 & 106 \\
25 & 104 & 102.8 & 106.7 & 108 \\
\hline
\end{tabular}

curves measured for the neat epoxy and nanocomposites of 0.5 wt.\% MWNT for the cycles A and B. No exothermic peaks were observed at $80^{\circ} \mathrm{C}$ in the materials investigated.

\subsubsection{Activation energy estimation}

The resulting $T_{g}$, determined by the tangent (delta) peak method, as a function of frequency is tabulated in Table 2 . As expected, an increase in test frequency results in an increase in $T_{g}$ (according to Arrhenius equation). As shown in Eq. (1), the activation energy of glass transition relaxation is proportional to the slop of a plot of the natural $\log$ of frequency vs. reciprocal of absolute $T_{g}(\mathrm{~K})$. Fig. 7 Shows a plot of $\ln (f)$ vs. $1 / T_{g}$ for the nanocomposites of cycle A, where $T_{g}$ is taken as the tangent (delta) peak. From the slop of the least squares regression line Eq. (1), the activation energy was calculated:

$\Delta H=-R \frac{d(\ln f)}{d\left(1 / T_{g}\right)}=-8.314 \times(-61,368)=510.2 \mathrm{~kJ}$

Table 3 shows the calculated activation energies for each of the four materials in two cycles. The results show an increase in the resin activation energy by the addition of nanotubes to composites of cycles A and B. The activation energy of the glass transition relaxation is the energy barrier that must overcome the occurrence of molecular motions causing the transition [29]. The estimation of the activation energy of the glass transition relaxation is quite useful because it can be used to estimate the temperature shift factors for time-temperature superposition without the construction of complete master curves [19,30-32]. Furthermore, using this

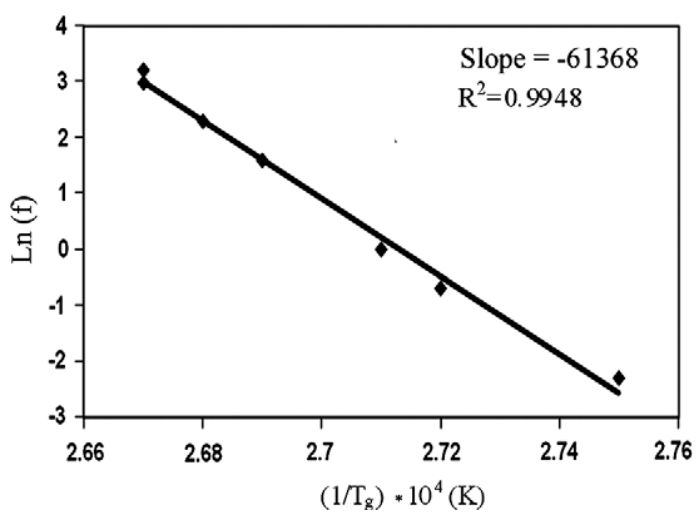

Fig. 7. $\operatorname{Ln}(f)$ vs. $1 / T_{g}$ for MWNT/epoxy cycle A sample.

Table 3

Activation energies for pure epoxy and two composite materials following cycles A and $\mathrm{B}$.

\begin{tabular}{lllll}
\hline Material & Epoxy (A) & MWNT/epoxy (A) & Epoxy (B) & MWNT/epoxy (B) \\
\hline$\Delta H(\mathrm{~kJ} / \mathrm{mol})$ & 455.5 & 510.2 & 482.3 & 519.87 \\
\hline
\end{tabular}


estimation, the modulus or compliance of a polymer at the end of its service life (i.e. 50 years) can be predicted by a single test at an elevated temperature rather than plotting a complete set a master curves $[19,30]$.

\subsubsection{Modeling of the viscoelastic behavior}

The Perez model was applied for the investigation of viscoelastic behavior. This model usually gives a good fit of COLE-COLE plots. The model leads to the following equation for the complex modulus [16]:

$E^{*}=E_{\infty}-\frac{E_{\infty}-E_{0}}{1+(i \omega \tau)^{-x}+Q(i \omega \tau)^{-x^{\prime}}}$

where $E_{0}$ and $E_{\infty}$ are the relaxed and unrelaxed modulus respectively.

Each transition is characterized by a pair of $\left(E_{0}, E_{\infty}\right)$. In the case of glass transition, $E_{0}$ is the equilibrium rubbery modulus, and $E_{\infty}$ is the modulus at the glassy regions just above $\alpha$ transition. $x$ and $x^{\prime}$ are related to the slopes $\mathrm{d} E^{\prime \prime} / \mathrm{d} E^{\prime}$ from one side to the other $\alpha$ relaxation. Finally, $Q$, the function of concentration of quasi-point defects, is related to maximum value of $E^{\prime \prime}$ and increases with increasing $Q$. The program of this model has been coded in MATLAB environment. Fig. 8a-d shows the COLE-COLE plots for two cycles $A$ and $B$. Their COLE-COLE plots are generally nonsymmetrical. The values of parameters of the model for epoxy and nanocomposites are shown in Table 4.
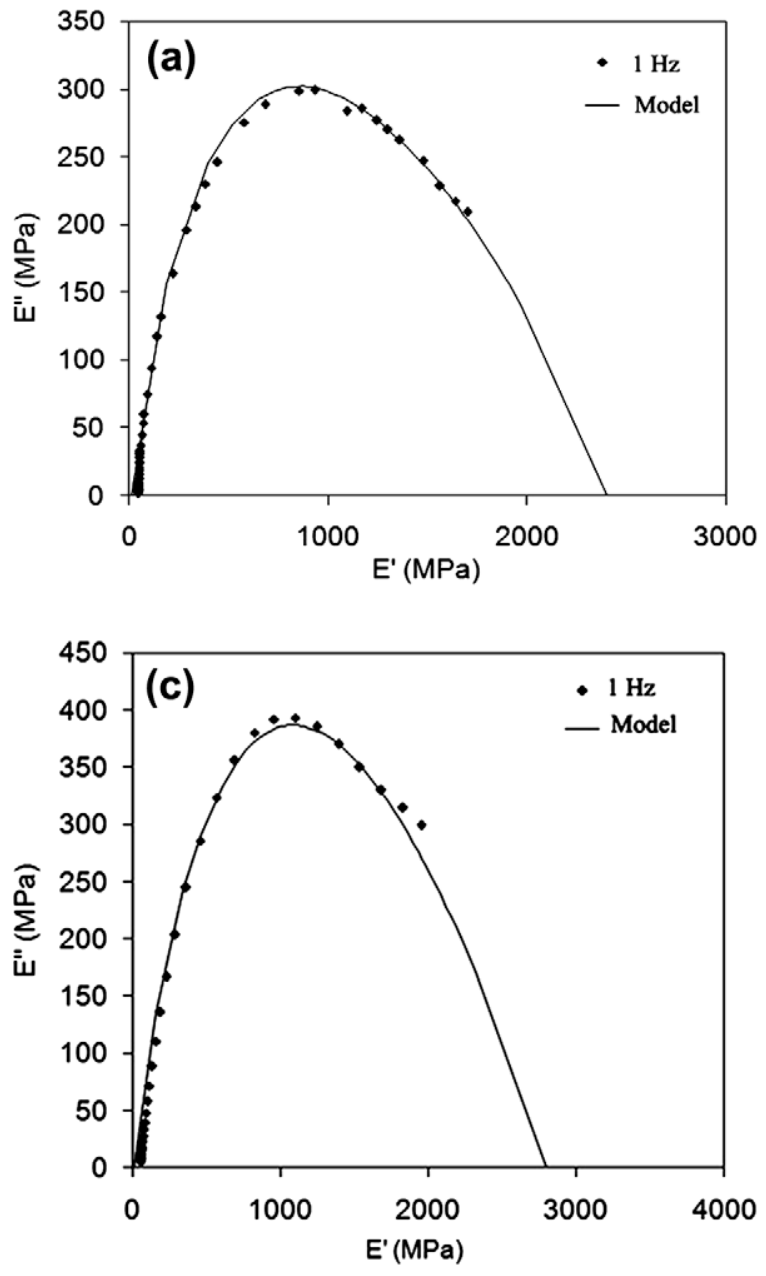

From the results presented in Table 4, we can draw the following conclusions.

$E_{\infty} / E_{0}$ increases when the nanotubes are added to epoxy in both cycles A and B. The increases are equal for both cycles.

The parameter $x$ shows a molecular motion. An increase in the value of $x$ indicates weaker molecular motion. The addition of nanotubes to the epoxy in both cycles led to an increase in the value of $x$.

The parameter $x^{\prime}$ accounts for the difficulty with which local shearing occurs and it is the most important parameter in Perez model. As soon as a local shearing takes place, the molecular orientation resulting from it makes molecular mobility more difficult. In other words, $x$ decreases rapidly when $x^{\prime}$ is low. In a cross-linked system the value of $x^{\prime}$ is low. For example, the values of $x^{\prime}$ for epoxy cycles A and B are 0.61 and 0.59 . These values are in good agreement with the values reported for DGEBA-DDM cross-linked system [16]. This occurs readily since the local shearing elongates the segment of the chain between two successive cross-links. The molecular orientation is more pronounced when this segment is small. The addition of nanotubes to epoxy decreases the value of $x^{\prime}$ from 0.65 to 0.55 and 0.59 to 0.52 for the cycles A and B respectively. Such behavior is probably related to the fact that $T_{g}$ value of a compatible system is intermediate between that of the components. In the nanocomposite and the epoxy sample with the cycle $B$, the chains are much more rigid than that of the cycle A. However, the rigidity improvement of the nanocomposite of the cycle $\mathrm{A}$ is higher than that of the cycle $\mathrm{B}$. These rigid chains could cause
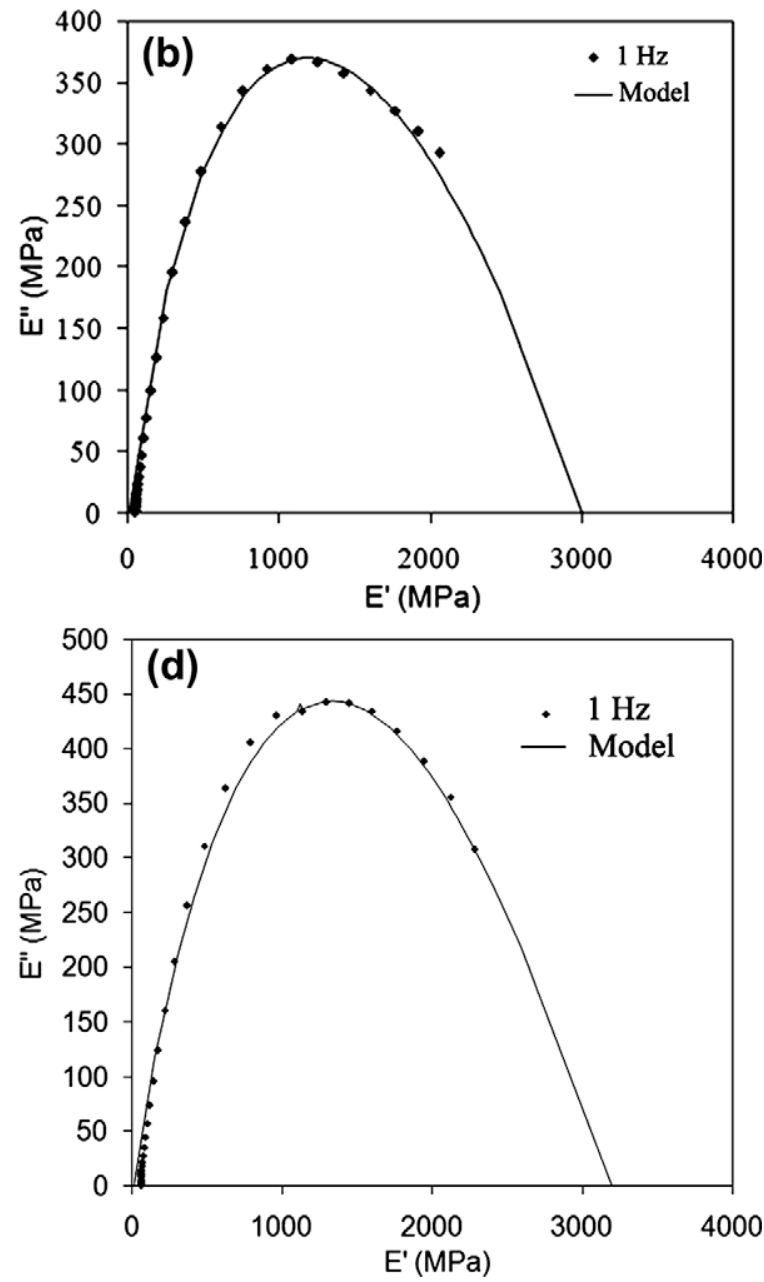

Fig. 8. COLE-COLE plots for (a) epoxy A, (b) MWNT/epoxy A, (c) epoxy B, and (d) MWNT/epoxy B. 
Table 4

The parameters used for the calculations of plots shown in Fig. 8a-d.

\begin{tabular}{llllll}
\hline Material & $E_{\infty} / E_{0}$ & $X^{\prime}$ & $X$ & $Q$ & $\tau_{\alpha}$ \\
\hline Epoxy (A) & 24 & 0.65 & 0.23 & 0.2 & 0.5 \\
MWNT/epoxy (A) & 30 & 0.55 & 0.24 & 0.28 & 0.5 \\
Epoxy (B) & 28 & 0.59 & 0.23 & 0.4 & 0.5 \\
MWNT/epoxy (B) & 32 & 0.52 & 0.25 & 0.6 & 0.5 \\
\hline
\end{tabular}

greater constraints on the mechanism of series correlation implied by the smaller value of $x^{\prime}[16]$.

The reduction of parameter $x^{\prime}$ shows that MWNT acts like a reinforcement of epoxy matrix in both curing cycles, but when the composite is cured during more time (cycle $\mathrm{B}$ ), the reduction is less noteworthy $[25,26]$.

\section{Conclusions}

Two different curing cycles have been used, $4 \mathrm{~h}$ at $80^{\circ} \mathrm{C}$, and the other curing cycle, $24 \mathrm{~h}$ at room temperature and post cured $4 \mathrm{~h}$ $80^{\circ} \mathrm{C}$. The reinforcement role of carbon nanotubes was assessed by the mechanical and viscoelastic tests and SEM observations. The results demonstrated the improvement of the mechanical and viscoelastic properties of epoxy and nanocomposite are controlled by curing cycle. It is obvious that the effect of nanotubes is more pronounced for a resin that was cured at a lower time. Also, the increment between the Young's modulus of the resin reinforced with $0.5 \mathrm{wt} . \%$ MWNT in each cycle is proportional to the increment in the pure epoxy the Young's modulus. The parameters of Perez model shows a good correlation between viscoelastic experimental results and the model used.

\section{Acknowledgements}

This work is supported by The Laboratoire d'ingénierie des matériaux, ENSAM-Paris and Department of Materials Science and Engineering, Iran University of Science and Technology (IUST).

\section{References}

[1] Iijima S. Helical microtubules. Nature 1991;354:56-8.

[2] IiJima S, Icihashi T. Single-shell carbon nanotubes of 1-nm diameter. Nature 1993;363:603-5.

[3] Bethune DS, Kiang CH, Devries MS, Gorman G, Savoy R, Vazquez J, et al. Cobaltcatalyzed growth of carbon nanotubes with single-atomic-layer walls. Nature 1993;363:605-7.

[4] Thostenson ET, Ren Z, Chow TW. Advances in the science and technology of carbon nanotubes and their composites: a review. Compos Sci Technol 2001;61:1899-912.

[5] Dresselhaus MS, Dresselhaus D, Ratio R. Physical properties of carbon nanotubes. London: Imperical College Press; 1999.

[6] Jin Z, Promoda KP, Xu G, Goh SH. Dynamic mechanical behavior of meltprocessed multi-walled carbon nanotube/poly(methacrylate) composite. Chem Phys Lett 2001;337:43-7.
[7] Liao YH, Marietta-Tondin O, Liang Z, Zhang C, Wang B. Investigation of the dispersion process of SWNT/SC-15 epoxy resin nanocomposite. Mater Sci Eng 2004;A385:175-81.

[8] Camponeschi E, Vance R, Al-Haih M, Garmestani H, Tannenbaam R. Properties of carbon nanotube-polymer composites aligned in a magnetic field. Carbon 2007;45:2037-46.

[9] Yaping Z, Abio Z, Qinghua C, Jiaoxia Z, Rongchang N. Functionalized effect on carbon nanotube/epoxy nanocomposite. Mater Sci Eng 2006;A435A436:145-9.

[10] Gojny FH, Schulte K. Functionalisation effect on the thermo-mechanical behavior of multiwall carbon nanotube/epoxy composite. Compos Sci Technol 2004;64:2303-8.

[11] Gong X, Liu J, Baskaran S, Voise RD, Young JS. Surfactant-assisted processing of carbon nanotube/polymer composite. Chem Mater 2000;12(4):1049-52.

[12] Gojny FH, Nstalczyk J, Roslaniec Z, Schulte K. Surface modified multi-walled carbon nanotubes in CNT/epoxy-composite. Chem Phys Lett 2003;370(5-6):; 820-824.

[13] Miyagawa H, Drzal LT. Thermo-physical and impact properties of epoxy nanocomposites reinforced by single-wall carbon nanotubes. Polymer 2004;45(15):5163-70.

[14] Mitchell CA, Bahar JL, Arepalli S, Tout JM, Krishnamoorti R. Dispersion of functionalized carbon nanotubes in polystyrene. Macromolecules 2002;35:8825-30.

[15] Abdalla M, Dean D, Adibempe D, Nyario E, Robinson P, Thompson G. The effect of interfacial chemistry on molecular mobility and morphology of multiwalled carbon nanotubes epoxy nanocomposites. Polymer 2007;48:5662-70.

[16] Perez J. Physic and mechanics of amorphos polymers. Rotterdam (Netherlands): A Balkema; 1998

[17] Pascault JP, Verdu J, Williams R. Thermosetting polymers. Basel (Switzerland): Eastern Hemisphere Distribution; 2002.

[18] Ferry JD. Viscoelastic properties of polymers. 2nd ed. New York: John Wiley; 1970.

[19] Rudin A. Polymer science and engineering. 2nd ed. New York: Academic Press: 1999.

[20] Hatakeyama T, Quinn F. Thermal analysis: fundamentals and application to polymer science. 2nd ed. Chister (UK): John Wiley \& Sons; 1999.

[21] Li G, Lee-Sullivan P, Thring R. Determination of activation energy for glass transition of an epoxy adhesive using dynamic mechanical analysis. J Therm Anal Calorim 2000;60(2):377-90.

[22] Ward I, Hadley D. An introduction to the mechanical properties of solid polymers. Chichester (UK): John Wiley \& Sons; 1993.

[23] White S, Mather P, Smith M. Characterization of the cure-state of DGEBA-DDS epoxy using ultrasonic, dynamic mechanical, and thermal probes. Polym Eng Sci 2002;42(1):51-66.

[24] ASTM Standard D638. Standard test method for tensile properties of plastics. PA (USA); American society for testing and material; 1996.

25] Guzman de villoria R, Miravete A, Cuartero J, Chiminelli A Tlosana N. Mechanical properties of SWNT/epoxy composite using to different curing cycles. Compos Part B: Eng 2006;37:273-7.

[26] Ci L, Bai J. The reinforcement role of carbon nanotubes in epoxy composite with different matrix stiffness. Compos Sci Technol 2006;66(3-4):599-603.

[27] Puglia D, Valentini L, Armentano I, Kenny JM. The Effect of single-walled carbon nanotubes incorporation on the cure reaction of epoxy resin and its detection by Raman spectroscopy. Diam Relat Mater 2003;12(3-7):827-32.

[28] Vlentini L, Armentano I, Puglia D, Kenny JM. Dynamics of amine functionalized nanotubes/epoxy composites by dielectric relaxation spectroscopy. Carbon 2004;42:323-9.

[29] La Plante G, Lee Sullivan P. Moisture effects on FM300 structural film adhesive: stress relaxation, fracture toughness, and dynamic mechanical analysis. J Appl Polym Sci 2005;95(5):1285-94.

[30] Kumar A, Gupta R. Fundamentals of polymer engineering. 2nd ed. New York: Marcel Dekker; 2003.

[31] Miyano Y, Nakada M. Accelerated testing for long-term durability of FRP laminates for marine use. J Compos Mater 2005;39(1):5-20.

[32] Goertzen WK, Kessler MR. Creep behavior of carbon fibre/epoxy matrix composites. Mater Sci Eng A 2006;421(1-2):217-25. 